\title{
Measures of nutrient processes as indicators of stream
}

\section{ecosystem health}

\author{
James W. Udy ${ }^{1, \uparrow, *}$, Christine S. Fellows ${ }^{1}$, Michael E. Bartkow ${ }^{1}$, Stuart E.

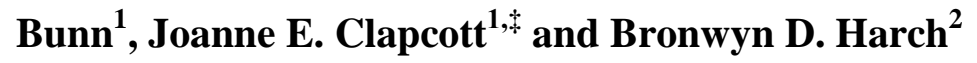

${ }^{1}$ Cooperative Research Centre for Freshwater Ecology, Centre for Riverine Landscapes, Griffith University, Nathan, Queensland, 4122, Australia.

${ }^{2}$ CSIRO Mathematical and Information Sciences, St. Lucia, Queensland, 4067, Australia.

*Author for Correspondence: Email: j.udy@uq.edu.au

$\dagger$ Present address: Centre for Water Studies, School of Engineering,

University of Queensland, Brisbane, Australia, 4072.

$\$$ Present address: School of Zoology, University of Tasmania, GPO Box 252-

05, Hobart, Tasmania, Australia, 7001.

Keywords: denitrification, stable nitrogen isotopes, chlorophyll a, catchment disturbance

This paper has not been submitted elsewhere in identical or similar form, nor will it be during the first three months after its submission to Hydrobiologia.

Running head: Nutrient processes as indicators 


\begin{abstract}
To better understand how freshwater ecosystems respond to changes in catchment land-use, it is important to develop measures of ecological health that include aspects of both ecosystem structure and function. This study investigated measures of nutrient processes as potential indicators of stream ecosystem health across a land-use gradient from relatively undisturbed to highly modified. A total of seven indicators (potential denitrification; an index of denitrification potential relative to sediment organic matter; benthic algal growth on artificial substrates amended with a) $\mathrm{N}$ only, b) $\mathrm{P}$ only, and c) $\mathrm{N}$ and $\mathrm{P}$; and $\delta^{15} \mathrm{~N}$ of aquatic plants and benthic sediment) were measured at fifty three streams in southeast Queensland, Australia. The indicators were evaluated by their response to a defined gradient of agricultural land-use disturbance as well as practical aspects of using the indicators as part of a monitoring program. Regression models based on descriptors of the disturbance gradient explained a large proportion of the variation in six of the seven indicators. With denitrification index, algal growth in $\mathrm{N}$ amended substrate, and $\delta^{15} \mathrm{~N}$ of aquatic plants demonstrating the best regression. However, the $\delta^{15} \mathrm{~N}$ value of benthic sediment was found to be the best indicator overall for incorporation into a monitoring program, as samples were relatively easy to collect and process, and were successfully collected at more than $90 \%$ of the study sites.
\end{abstract}




\section{Introduction}

To fully assess ecosystem health it is necessary to investigate both ecosystem structure and function. Ecosystem structure identifies biological, chemical and physical patterns, while ecosystem function involves quantification of the processes that occur within an ecosystem. Ecosystem processes can help identify the vigour or resilience of a system (Rapport et al., 1998) as well as being a direct measurement of ecosystem services, such as nutrient removal by denitrification (Udy \& Bunn, 2001).

Measurements of ecosystem processes have only recently been used to assess the health of aquatic systems. The focus to date has been on benthic metabolism (Fellows et al., this issue; Hill et al., 2000; Bunn et al., 1999), but nutrient processes are also likely to be useful indicators of stream health because they respond to changes resulting from catchment disturbance, such as increased sediment and nutrient loads. Methods used to assess aspects of nutrient cycling in streams include (1) measuring rates of particular processes under controlled conditions (e.g. denitrification, Royer et al. (2004); nitrification, Strauss \& Lamberti (2000)), and (2) in situ nutrient additions (e.g. enrichment level additions, Mulholland et al. (2002); stable isotope additions, Peterson et al. (2001); nutrient limitation assays, Tank \& Dodds (2003)).

Denitrification is a nutrient cycling process that is of particular interest from a management perspective because it converts nitrate $\left(\mathrm{NO}_{3}{ }^{-}\right)$to $\mathrm{N}$-containing gas, effectively removing $\mathrm{N}$ from the aquatic environment (Seitzinger, 1988; Knowles, 
1982). Similar to other in-stream microbial processes, rates of denitrification should respond to changes in sediment, carbon, and nitrogen loads and changes in temperature regime associated with catchment disturbance such as clearing of native vegetation, including riparian zone vegetation, and other land-use changes such as conversion to or intensification of agriculture. Denitrification is carried out predominately by heterotrophic microbes using $\mathrm{NO}_{3}{ }^{-}$as an electron acceptor during the oxidation of organic carbon under anoxic conditions (Knowles, 1982). Higher rates of denitrification would therefore be expected with the increased supplies of $\mathrm{N}$ and organic carbon associated with increasing levels of catchment disturbance. However, denitrification does not necessarily increase with increasing nutrient load when organic forms dominate the load (Burford \& Longmore, 2001; Heggie et al., 1999; Sloth et al., 1995), suggesting that it is important to consider the rate relative to organic matter supply.

The response of phytoplankton and benthic algal communities to nutrient additions has been used in both estuarine and freshwater ecosystems to determine the limiting nutrient in an environment and the importance of nutrient availability relative to other environmental factors in controlling phytoplankton and benthic algal growth (Hadwen et al., 2005; Mosisch et. al. 1999; O’Donohue \& Dennison 1997). High algal biomass is often considered a symptom of unhealthy streams, as minimally impacted systems tend to have low nutrient concentrations and riparian shading which limits algal biomass (Mosisch et al., 1999). Benthic primary production is generally greater than that in the water column in small streams (Keithan \& Lowe 1985; Davies 1994), and therefore the current study 
focused on benthic algal growth. Measurement of algal biomass accrual on bare substrate serves as a measure of algal growth rate (Kevern \& Ball 1965), and use of artificial substrates provides a standardized method for inter-site comparisons and the opportunity to manipulate nutrient regimes (e.g. Mosisch et al., 2001).

The $\mathrm{N}$ stable isotope values of organisms reflect both their sources of $\mathrm{N}$ and processes influencing the cycling of N (Peterson \& Fry, 1987), and therefore could potentially serve as indicators of ecosystem health. Recently, $\delta^{15} \mathrm{~N}$ values of aquatic plants have been employed to trace the impacts of anthropogenic nitrogen on estuarine ecosystems (Costanzo et al., 2001, 2005; Udy \& Dennison 1997a). Nitrogen stable isotopes of animals have been used in a similar manner for assessing freshwater ecosystems, including insectivorous birds in the riparian zone of streams (Wayland \& Hobson 2001) and freshwater mussels (McKinney et al., 2002). Microbial processing of $\mathrm{N}$ has been shown to elevate $\delta^{15} \mathrm{~N}$ values of organic matter via decomposition (Owens, 1985) and those of seagrass by denitrification (Fourqurean et al., 1997). Additionally, Udy \& Bunn (2001) found a strong positive correlation between the percentage of land cleared in a catchment and the $\delta^{15} \mathrm{~N}$ of aquatic plants, suggesting that the nitrogen cycle in these creeks had in some way been influenced by catchment clearing. Although stable isotope values are a structural aspect of ecosystems, the findings of Udy \& Bunn (2001) and other studies suggest that these values might represent an integrated signature of $\mathrm{N}$ cycling processes, with more enriched $\delta^{15} \mathrm{~N}$ values being associated with greater levels of catchment disturbance. 
The current study aimed to measure the response of various nutrient process indicators to a diffuse land-use gradient (disturbance gradient) as part of a regional study developing indicators of stream ecosystem health in southeast Queensland, Australia (Abal et al., 2005). One measure was chosen from each of the three major groups of methods for measuring nutrient processes identified in the literature: rates of denitrification (a measure of an individual $\mathrm{N}$ cycling process); benthic algal growth on nutrient-amended substrates (an in situ addition method); and $\delta^{15} \mathrm{~N}$ values of aquatic plants and sediment to provide an integrated signature of $\mathrm{N}$ cycling processes.

\section{Methods}

\section{The Southeast Queensland Study}

The current study on nutrient process indicators forms one component of the project on Design and Implementation of a Baseline Monitoring program for first to third order streams in southeast Queensland, Australia (DIBM) (Abal et al., 2005). The DIBM study was a key component of the scientific research undertaken as part of the Southeast Queensland Regional Water Quality Strategy for what is now known as the Moreton Bay Waterways and Catchments Partnership. The goal of the study was to develop a regional stream health monitoring program that could be used to measure and report on current status and future changes in ecological health. The DIBM study evaluated a broad range of indicators against a known disturbance gradient to identify those that best responded. This approach was based on that used by the Group of Experts on Environmental Pollution (GEEP) to detect anthropogenic impacts in marine 
systems (Bayne et al., 1988; Addison \& Clarke 1990; Stebbing \& Dethlefsen 1992).

The study area covers over $22,000 \mathrm{~km}^{2}$ and includes six catchments and 15 major rivers of the Moreton region of Queensland, Australia and incorporates 19 local government regions. The climate is subtropical, with just over half $(55 \%)$ of the rainfall typically occurs during the summer wet season (December to March). Stream flow varies greatly with season and many low-order streams flow only during the wet season.

The major land uses in southeast Queensland are grazing and cropping, and these were chosen as the primary disturbance gradient against which indicators were evaluated. The disturbance gradient was quantified using both GIS data and field measurements. Data on the percentage of catchment cleared as well as percentages under specific land uses was derived from GIS. Other attributes or descriptors of the disturbance gradient were measured in the field, including channel and riparian zone conditions. The disturbance gradient descriptors were assigned to one of six broad categories to simplify reporting and allow direct comparison of different indicators (Table 1). A suite of potential indicators of stream health were measured at 53 sites on first to third order streams that varied in the degree of land-use disturbance (from undisturbed rainforest to cleared catchments with intensive cropping on the flood plain) in September and October 2000. These indicators fell into five groups: macroinvertebrates, fish, water chemistry, nutrients and nutrient cycling, and benthic metabolism. The response 
of these indicators to descriptors of reach and catchment scale disturbance was investigated using generalised linear regression modeling (see 'Data analysis' for details). This paper focuses on the results from measures of nutrients and nutrient cycling component of the DIBM study. Results from the other four groups of indicators can be found in this issue (Kennard et al., this issue; Fellows et al., this issue) as well as in Smith \& Storey (2001) and Abal et al. (2005).

\section{Disturbance gradient descriptors}

Measurements made at the sites and catchment GIS data were used to define more than 80 descriptors of the catchment land-use disturbance gradient. A subset of the descriptors was chosen for the analysis of each group of indicators based on conceptual models of factors influencing the indicators. For the nutrient process indicators discussed in the current study, a subset was chosen which included 15 descriptors from 5 categories (Table 1). Land-use descriptors \% Cleared and land-use categories were obtained using GIS analysis of subcatchment boundaries and State Land and Tree Survey (SLATS) data from 1999 (Queensland Natural Resources and Mines). Channel Condition was assessed using a method modified from Rosgen (1994). Two measures of Riparian conditions were employed: a categorical assessment of riparian vegetation over the $100 \mathrm{~m}$ study reach (modified from Anderson, 1993) and a quantitative measure of riparian canopy cover at the site where nutrient processes sampling was conducted using fish-eye lens photography (Bunn et al., 1999). Nine descriptors were chosen from the Water and sediment chemistry category. Most of these descriptors were derived from the analysis of three water samples collected at each site: 1) unfiltered for 
total ionic composition and turbidity, 2) unfiltered for total concentrations of nutrients, and 3) filtered for concentrations of dissolved nutrients. Principal components analysis (PCA) was used to reduce the total number of water chemistry variables. PCA variable 1 explained $53 \%$ of the variation in site water chemistry and represented primarily inorganic ions (e.g. alkalinity, conductivity, chloride). In addition to PCA variable 1 being used in analysis to characterize the ionic composition of the water the major nutrients (total and dissolved) were also used individually (nitrate + nitrite, ammonium, total nitrogen, filterable reactive phosphorous, and total phosphate). However, as the concentrations of these variables were not normally distributed the data was graphed and categorized into groups where the data showed natural breaks. Nitrate + nitrite is referred to from here forward as $\mathrm{NO}_{3}{ }^{-}$. Maximum water temperature and minimum dissolved oxygen (\% saturation) of the stream during a 24 hour period were recorded by a data logger (TPS 601). Sediment samples of the top $5 \mathrm{~cm}$ of the stream bed were collected at each site using a modified $60 \mathrm{ml}$ plastic syringe, and $\% \mathrm{C}$ of the sediment was determined by weighing the dry sediment (dried at $60^{\circ} \mathrm{C}$ until no further change) before and after incineration at $400^{\circ} \mathrm{C}$. For evaluating two of the nutrient process indicators, the $\delta^{15} \mathrm{~N}$ values of aquatic plants and benthic sediment, denitrification potential was considered a disturbance gradient descriptor in the Water and sediment chemistry category. The inclusion of this indicator as a descriptor was based on the findings of Fourqurean et al. (1997) that suggest increased rates of denitrification result in enriched $\delta^{15} \mathrm{~N}$ signatures. The only descriptor of In-stream habitat used was the \% of fine sediment (silts and 
mud fraction) present on the stream bed. No descriptor of Flow Related categories was chosen for analysis.

\section{Denitrification}

\section{Rates of denitrification potential}

Rates of denitrification potential were determined using the acetylene block method (similar to Holmes et al., 1996 and Pfenning \& McMahon, 1997). Eight replicate sediment samples were collected from each site in $60 \mathrm{ml}$ cut-off syringes. Stoppers were placed in both ends of the corer to reduce the gas exchange between the sediment and the air during transport. Two litres of unfiltered water was also collected at each site and transported with the sediment samples on ice.

Within 8 hours of collection, four replicate bottles were prepared for each site in the laboratory. Each sample bottle received the top $2 \mathrm{~cm}$ of sediment from two cores $(2 \times 20 \mathrm{ml})$ and an equivalent volume $(40 \mathrm{ml})$ of stream water from that site. Because the goal was to assess rates of potential denitrification, nitrate was added to increase the concentration in the sediment slurries by $50 \mu \mathrm{M}$ to ensure nitrate was available to denitrifiers. The bottles were sealed with a rubber septum and the headspace was purged with $\mathrm{N}_{2}$ for two minutes to create anoxic conditions (sufficient to lower dissolved oxygen in the slurry $<0.2 \mathrm{mg} \mathrm{l}^{-1}$ ). Twenty-five $\mathrm{ml}$ of gas was then removed from the headspace and replaced with $20 \mathrm{ml}$ of clean acetylene gas. The injection of acetylene inhibits the reduction of nitrous oxide 
$\left(\mathrm{N}_{2} \mathrm{O}\right)$ to nitrogen, allowing the denitrification rate to be estimated by the rate at which nitrous oxide accumulates in the head space (Tiedje et al., 1989). The concentration of nitrous oxide was measured on a Hewlett Packard 6890+ gas chromatograph (GC) equipped with an alumina oxide PLOT column and splitless inlet system (flow: $5.9 \mathrm{~mL}$ minute ${ }^{-1}$, oven temperature: $50^{\circ} \mathrm{C}$ ) and an electroncapture detector (ECD). Samples were maintained at a room temperature (19$\left.21^{\circ} \mathrm{C}\right)$ that was similar to the median stream water temperatures $\left(16-23^{\circ} \mathrm{C}\right)$. Gas samples were taken every 2-3 h, with a minimum of 6 samples being collected and analysed on the GC for $\mathrm{N}_{2} \mathrm{O}$. The increase in $\mathrm{N}_{2} \mathrm{O}$ over time for the linear part of the curve (always between the second and fifth sample) was used to calculate the rate of denitrification. A correction was made for $\mathrm{N}_{2} \mathrm{O}$ dissolved in the $80 \mathrm{ml}$ of sediment/water slurry following Weiss \& Price (1980) with results reported as the mean $\mu \mathrm{mol} \mathrm{N} \mathrm{m} \mathrm{N}^{-1} \pm 1$ standard error for each site.

\section{Denitrification index}

Burford \& Longmore (2001) have combined data from many studies to show that the rate of denitrification does not represent a linear relationship with nutrient load. Denitrification may be supported either by $\mathrm{NO}_{3}{ }^{-}$from the overlying water column or by $\mathrm{NO}_{3}{ }^{-}$generated by nitrification of ammonium in adjacent zones with sufficient oxygen available (coupled nitrification-denitrification, Vanderborght \& Billen 1975; Nishio et al., 1983). The denitrification rate at a site is expected to increase as the nitrogen availability increases up to a certain point. However, when a system receives large inputs of organic matter, and most of the nitrogen load is organic and/or ammonium, denitrification rates are likely to reduce 
dramatically due to low $\mathrm{NO}_{3}{ }^{-}$concentrations. Increased organic matter decomposition and the associated extensive anoxia inhibit nitrification, therefore limiting the $\mathrm{NO}_{3}{ }^{-}$available for denitrification (Van Luijn et al., 1999). To account for the potential influence of organic matter load, a denitrification index was calculated to be trialled as an indicator along with rates of denitrification. The index was derived by calculating the ratio between the rate of denitrification potential and the sediment organic carbon concentration $(\% \mathrm{C})$.

\section{Algal Bioassays and Nutrient Limitation}

Benthic algal growth was measured using small pots $(6 \mathrm{~cm}$ diameter plastic containers) attached to wooden boards and placed on the stream bed. The surface of the pots was approximately $5 \mathrm{~cm}$ above the streambed and the lids consisted of $100 \mu \mathrm{m}$ mesh screen to provide a substrate for the colonisation of benthic algae and to allow for nutrient diffusion. The four treatments used were control (no nutrient added); nitrogen only $\left(2 \mathrm{~g} \mathrm{~N}_{\text {as }} \mathrm{NO}_{3}{ }^{-}\right.$and $\left.\mathrm{NH}_{4}{ }^{+}\right)$; phosphorous only $(0.4 \mathrm{~g} \mathrm{P}$ as $\left.\mathrm{PO}_{4}{ }^{3-}\right)$; and nitrogen + phosphorous $\left(2 \mathrm{~g} \mathrm{~N}\right.$ as $\mathrm{NO}_{3}{ }^{-}$and $\mathrm{NH}_{4}{ }^{+}$, and $0.2 \mathrm{~g} \mathrm{PO}_{4}{ }^{3-}$ (combined $\mathrm{N}$ and $\mathrm{P}$ product)). The nutrient treatments were created by placing the appropriate quantity of Osmocote slow release fertiliser pellets (4 month $80 \%$ release at $21^{\circ} \mathrm{C}$; Osmocote product data) in the bottom of each pot so that a slow diffusion of the nutrient across the screen ensured the nutrient was always available for algal growth. Different treatments were placed perpendicular to the stream flow to minimise contamination between treatments. After four weeks in the field, pots were removed from the stream and the mesh was cut at the circumference of the lid. Mesh and attached algae were collected and placed in 
aluminium foil envelopes and stored at $-4^{\circ} \mathrm{C}$. In the laboratory, chlorophyll $a$ (Chl $a$ ) analysis was performed according to the methods of Parsons et al. (1984) using pigment extraction in $90 \% \mathrm{v} / \mathrm{v}$ acetone. Following extraction, the solution was centrifuged and the supernatant analysed for Chl $a$ concentration by spectrophotometer, with units expressed as concentration per area of mesh $(\mathrm{mg}$ Chl $a \mathrm{~m}^{-2}$ ). Algal growth on the control treatment was used as an indicator of benthic primary production as part of the benthic metabolism group of indicators and therefore most of the results for this treatment are presented in Fellows et al. (this issue).

\section{Stable Isotope Analysis $\left(\delta^{15} N\right)$}

Sediment samples were collected from all sites with sediment-dominated stream beds or where pockets of sediment could be found. Modified $60 \mathrm{ml}$ syringes were used to collect the top $3 \mathrm{~cm}$ of sediment, which presumably included microalgae growing on the surface as well as any other organic matter present. Aquatic plants (filamentous algae/macrophyte) were collected from all sites where they were present by hand or using forceps. All samples were stored at $-4^{\circ} \mathrm{C}$. In the laboratory, plant samples were washed clean of sediment, oven dried at $60^{\circ} \mathrm{C}$ for 24 hours and ground with a mortar and pestle. Sediment samples $(n=3)$ were dried at $60^{\circ} \mathrm{C}$ for at least three days and ground with a mortar and pestle. Dried samples were then weighed out into tin capsules, combusted and analysed with a continuous flow-isotope ratio mass spectrometer (Micromass, UK) to obtain $\delta^{15} \mathrm{~N}$ values. Ratios of ${ }^{15} \mathrm{~N} /{ }^{14} \mathrm{~N}$ are expressed as the relative per mil (\%o) difference between the sample and conventional standards $\left(\mathrm{N}_{2}\right.$ in air $)$ as follows: 


$$
\delta \mathrm{X}=\left[\mathrm{R}_{\text {sample }} / \mathrm{R}_{\text {standard }}-1\right] \times 1000(\%) ;
$$

where $\mathrm{X}={ }^{15} \mathrm{~N}$ and $\mathrm{R}={ }^{15} \mathrm{~N} /{ }^{14} \mathrm{~N}$.

\section{Data analysis}

A protocol for data analysis was devised based on the GEEP approach (Bayne et al., 1988). The goals were to simplify the process of comparing the seven indices of nutrient processes (Denitrification; Denitrification/\%Carbon; chlorophyll $a$ on artificial substrate $+\mathrm{N},+\mathrm{P}$ and $\mathrm{N}+\mathrm{P}$; and $\delta^{15} \mathrm{~N}$ of aquatic plants and sediment) and to allow direct comparison of all the results across the various ecological indicators used in the DIBM study. Distributional properties of the data were checked and any transformations required for subsequent statistical analyses performed (to meet assumptions of normality and transform negative values). Preliminary investigation of relationships between descriptors of the disturbance gradient and nutrient process indices were explored using scatter plots and Spearman rank correlation coefficients. A Generalised Linear Modeling (GLM) framework was used to determine whether particular indices could be used to detect the underlying disturbance gradient. Stepwise regression modeling was employed with simultaneous forward and backward searching and the Akaike Information Criterion (AIC) was used for variable selection. The modeling procedure identified which disturbance descriptors accounted for the variability in each of the indices, and additionally quantified the proportion of variation accounted for by each descriptor. Indicators were assessed in terms of the 
approximate amount of variation explained (approximate $\mathrm{R}^{2}$ value) by the full model and the proportion of this variation explained by individual descriptors of the disturbance gradient. Data was analyzed using the S-PLUS 2000 Professional Release 3 (MathSoft Inc.) statistical software.

A limited number of disturbance descriptors were included in the GLM to avoid over-parameterization of the regression models. Of the more than eighty disturbance descriptors relating to the catchment land-use disturbance gradient, 15 descriptors from 5 categories (Table 1) were chosen as the most appropriate for analysis of the nutrient process indicators. The descriptors were chosen based on conceptual models of the factors most likely to influence nutrient processes and to avoid multicollinearity. These 5 categories were described as containing measures made at the catchment scale (Land-use), the reach scale (Channel Condition, Riparian Conditions, and In-stream Habitat), or influenced by both scales (Water and Sediment Chemistry).

Additional univariate statistical analyses were performed to explore relationships of interest, including simple linear regression analysis of denitrification rate and $\% \mathrm{C}$ and the $\delta^{15} \mathrm{~N}$ values of aquatic plants and benthic sediment. A two-way ANOVA was used to investigate the response of benthic algal growth to differing nutrient treatments on the artificial substrates (factors $=$ treatment and site).

\section{Results}




\section{Denitrification}

Rates of potential denitrification in the study area were measured at 45 of the 53 sites used in this study, with values ranging from 4 to $950 \mu \mathrm{mol} \mathrm{N} \mathrm{m} \mathrm{N}^{-2} \mathrm{~h}^{-1}$ and most rates being below $150 \mu \mathrm{mol} \mathrm{N} \mathrm{m} \mathrm{N}^{-2}$ (Figure 1). Two of the highest rates (950 and $203 \mu \mathrm{mol} \mathrm{N} \mathrm{m} \mathrm{N}^{-1}$ ) were observed downstream of sewage treatment plants and another high rate $\left(230 \mu \mathrm{mol} \mathrm{N} \mathrm{m} \mathrm{m}^{-2} \mathrm{~h}^{-1}\right)$ was recorded in an urban stream with high nitrate concentrations. However, other sites with perceived high nutrient inputs, due to their agricultural or urban catchment land-uses, had relatively low rates of denitrification. There was also no significant correlation between the denitrification rate and $\% \mathrm{C}$ in the sediment ( $\mathrm{p}>0.05$; Figure 1$)$.

Regression modelling showed that just over half of the variability in potential denitrification rate could be explained by the disturbance gradient descriptors Water and sediment chemistry (45\%), In-stream habitat (5\%) and Land-use (1\%)(Table 2). The ability of the disturbance gradient descriptors to explain the variability in the denitrification index (Denitrification / \% C) was even greater, with $\mathrm{R}^{2}=79 \%$ (Figure 2 ). For the denitrification index, all the model variables selected came from the Water and sediment chemistry category. For both denitrification rate and denitrification index, the variables within Water and sediment chemistry category that had a positive effect were nitrate and total $\mathrm{P}$ concentrations and temperature, while total $\mathrm{N}$ had a negative relationship. 


\section{Algal Bioassays}

Of the artificial substrates deployed, at least one replicate was successfully retrieved from a total of 30 sites. The primary reasons for failing to obtain data at the other sites were vandalism, burial by sediments, and exposure due to falling stream levels. The response of algae to the nutrient additions varied greatly across sites, with the Chl $a$ concentration on pots with both $\mathrm{N}$ and $\mathrm{P}$ added being up to 50 times those on the control pots at the same site and the average increase in Chl $a$ on the N+P pots being 2.4 times that of the control. The Chl $a$ concentrations across different sites, but within the same treatment, also demonstrated a large amount of variation, with approximately two orders of magnitude range within each treatment (control 0.9-77 mg Chl $a \mathrm{~m}^{-2} ;+\mathrm{P} 0.7$ to $67 \mathrm{mg} \mathrm{Chl} a \mathrm{~m}^{-2} ;+\mathrm{N} 0.3$ to $72 \mathrm{mg} \mathrm{Chl} a \mathrm{~m}^{-2} ;+\mathrm{N}+\mathrm{P} 0.6$ to $106 \mathrm{mg} \mathrm{Chl} a \mathrm{~m}^{-2}$ ).

Although the range in $\mathrm{Chl} a$ values was similar for all treatments, both treatment and site were significantly different using a 2 way ANOVA ( $p<0.0001$ for both). The interaction term was not significant, and multiple comparisons indicated that the mean value of Chl $a$ for all sites was significantly $(\mathrm{p}<0.05)$ higher in the N+P (33 mg Chl $a \mathrm{~m}^{-2}$ ) treatment compared to the other three treatments. The $+\mathrm{N}(21$ $\mathrm{mg} \mathrm{Chl} a \mathrm{~m}^{-2}$ ) treatment was also greater than the control (13 $\left.\mathrm{mg} \mathrm{Chl} a \mathrm{~m}^{-2}\right)$. The mean $\mathrm{Chl} a$ on the $\mathrm{P}\left(16 \mathrm{mg} \mathrm{Chl} a \mathrm{~m}^{-2}\right)$ treatment was not significantly different ( $p>0.05)$ from either the control or $\mathrm{N}$ treatments.

Most of the observed variability among sites in Chl $a$ on the $+\mathrm{N}$ and $\mathrm{N}+\mathrm{P}$ treatments could be explained by the disturbance gradient $\left(\mathrm{R}^{2}=80 \%\right.$ and $68 \%$, 
respectively; Table $2 \&$ Figure 3). Light availability (\% riparian zone and $\%$ fine sediment) was an important aspect of the disturbance gradient in all nutrient treatments $(+\mathrm{N},+\mathrm{P}, \mathrm{N}+\mathrm{P})$. While nutrient availability (Water and sediment chemistry) was important for the $+\mathrm{N}$ and $+\mathrm{P}$ treatments, but not in the $\mathrm{N}+\mathrm{P}$ treatment.

Riparian conditions (27\%), Water and sediment chemistry (26\%) and In-stream habitat (27\%) were equally weighted in there influence on Chl $a$ for the $+\mathrm{N}$ treatment, while Riparian conditions (33\%) and In-stream habitat (33\%) contributed most of the explained variation $(68 \%)$ for the $+\mathrm{NP}$ treatment, with Water and sediment chemistry contributing only $2 \%$. The descriptor used in the Riparian conditions category was \% riparian zone, which had a negative relationship with Chl $a$. Percent fine sediment in the In-stream habitat category also showed a negative relationship with $\mathrm{Chl} a$ in both the $\mathrm{N}+\mathrm{P}$ and $+\mathrm{N}$ treatments. Only $37 \%$ of the variation in $\mathrm{Chl} a$ concentrations for the $+\mathrm{P}$ treatment could be explained by the disturbance gradient, with only two descriptors, total $\mathrm{N}$ in the Water and sediment chemistry category (22\%) and \% riparian cover in the Riparian conditions category (15\%), contributing to the model.

\section{Stable isotopes of nitrogen $\left(\delta^{15} N\right)$}

The $\delta^{15} \mathrm{~N}$ of filamentous algae and macrophytes at the 26 sites where they were present ranged between $-1.2 \%$ and $26 \%$, with a median value of $4 \%$. The $\delta^{15} \mathrm{~N}$ value of sediment from 48 sites had the same median value (4\%) but a smaller range ( -1 to $16 \%$ ) than aquatic plants. The relationship between $\delta^{15} \mathrm{~N}$ values of 
aquatic plants and sediment was significant $(\mathrm{p}<0.05)$, with an $\mathrm{R}^{2}$ of $55 \%$ (Figure $4)$.

Regression modelling showed that much of the observed variation in $\delta^{15} \mathrm{~N}$ values of aquatic plants and sediment could be explained by disturbance gradient descriptors in the Water and sediment chemistry category, and to a lesser extent, the Land-use category (Table 2). Eighty percent of the variation in $\delta^{15} \mathrm{~N}$ values of aquatic plants could be explained by a linear regression model that included only two descriptors (Figure 5): potential denitrification rate with a positive relationship (67\%, Water and sediment chemistry) and land-use category with a negative relationship (Land-use). The model for sediment $\delta^{15} \mathrm{~N}$ values explained less variation (62\%), with $55 \%$ contributed by Water and sediment chemistry descriptors and $7 \%$ by a Land-use descriptor (land-use category with a negative relationship). Similar to the model for aquatic plants, potential denitrification rate was one of the descriptors chosen and had a positive relationship. Other descriptors included $\mathrm{NO}_{3}^{-}$and maximum temperature with positive slopes, and total $\mathrm{N}$ and $\% \mathrm{C}$ in sediment with negative slopes.

\section{Discussion}

Although there are potentially multiple criteria on which to evaluate the effectiveness of potential indicators of ecosystem health, the current study focused on how much of the observed variation in an indicator could be explained by descriptors of the disturbance gradient. In this sense, good indicators had high $\mathrm{R}^{2}$ values for the stepwise regression models developed. Six of the seven indicators were good using this criterion, with $\mathrm{R}^{2}$ values of greater than $50 \%$. The exception 
was Chl $a$ on $+\mathrm{P}$ artificial substrates with a value of $37 \%$. The three indicators for which the highest proportion of variation (nearly or exactly $80 \%$ ) was explained by descriptors of the disturbance gradient were the denitrification index, Chl $a$ on $+\mathrm{N}$ artificial substrate, and $\delta^{15} \mathrm{~N}$ values for plants. Regression models for all the indicators included descriptors from both reach and catchment scales, with the exception of the $\mathrm{N}+\mathrm{P}$ treatment of benthic algal growth which only had reach scale descriptors. Additional factors that will be considered qualitatively below for evaluating the indicators include the spread of values observed, level of technical difficulty, cost, and applicability to a wide range of sites.

\section{Denitrification}

The denitrification index (denitrification potential rate/sediment $\% \mathrm{C}$ ) was a better indicator than potential denitrification rate alone, with a model $\mathrm{R}^{2}$ value nearly $30 \%$ greater. Calculation of the index requires the additional analysis of sediment for $\% \mathrm{C}$, but this represents a relatively small increase in technical difficulty and cost. Both indicators can be applied to streams that have at least some sediment substrate present, which for this study was greater than $90 \%$ of the sites. The indicators had similarly good spread of values, at greater than two orders of magnitude for both. Both indicators have the drawback of being relatively technically difficult and time intensive (laboratory aspect of potential denitrification measurement).

The fact that the regression model for denitrification index was better than that for rate of denitrification potential supports the idea that organic matter is an 
important control on denitrification rate. The stepwise modelling process for both indicators included $\mathrm{NO}_{3}{ }^{-}$with a positive slope and total $\mathrm{N}$ with a negative slope, suggesting a reduction in denitrification with increasing forms of $\mathrm{N}$ other $\mathrm{NO}_{3}{ }^{-}$. For potential denitrification rate, $\% \mathrm{C}$ was also chosen by the stepwise modelling process and showed a negative slope. Denitrification efficiency (rate relative to $\mathrm{N}$ load) has been shown to decrease at high concentrations of organic matter (Burford \& Longmore, 2001; Heggie et al., 1999; Sloth et al., 1995). From the perspective of managing in-stream $\mathrm{N}$ loads, denitrification rate relative to load is important. Characterising stream $\mathrm{N}$ loads was beyond the scope of the current study, but using rates of denitrification potential as an indicator should be particularly valuable at sites where 'load-based' monitoring is a specific concern, such as downstream of point source discharges of nitrogen such as sewage treatment plants. Broad scale survey of denitrification rates in streams is also important for the development of nutrient budgets and to improve predictive models of catchment nitrogen loads (Bartkow \& Udy, 2004) and to quantify the contribution of this ecosystem service to nutrient load reduction.

\section{Algal growth under nutrient enrichment}

Of the three nutrient-enriched artificial substrates, Chl $a$ on $+\mathrm{N}$ was the best indicator as judged by model $\mathrm{R}^{2}$, followed closely by $\mathrm{N}+\mathrm{P}$. The $+\mathrm{P}$ treatment had a substantially lower $\mathrm{R}^{2}$, suggesting that we did not measure the environmental drivers that are the major influence on this treatment. All treatments showed a good spread in values, with ranges of approximately two orders of magnitude. The method of using nutrient amended artificial substrates has a relatively low 
level of technical difficulty and is relatively inexpensive, but does require return trips to sites 4 weeks after initial deployment. The greatest limitation for this group of indicators was the relatively low (60\% of sites) retrieval rate of the artificial substrates.

In addition to being good indicators in terms of the $\%$ variation explained by the disturbance gradient, benthic algal growth on nutrient-enriched substrates provides insight into several different aspects of stream health. The control treatment provides an indicator of current environmental conditions in a stream (Fellows et al., this issue). The response of the algae to the $\mathrm{N}$ and $\mathrm{N}+\mathrm{P}$ treatments, across all sites, demonstrates that $\mathrm{N}$ was the primary limiting nutrient for algal growth in freshwater streams of S.E. Queensland. This is consistent with previous research that has demonstrated primary $\mathrm{N}$ limitation in the Mary River Catchment, on the northern boundary of this study region (Mosisch et al., 1999). However the significantly larger algal biomass on the $\mathrm{N}+\mathrm{P}$ treatment compared to the $\mathrm{N}$ only treatment, and the fact that the $\mathrm{P}$ only treatment at some sites demonstrated a large fertilisation response (up to 4 times control), suggests that the availability of $\mathrm{P}$ is still important in limiting algal growth in some S.E. Queensland sub-catchments. While not a focus of the current study, at individual sites, the four treatments taken in combination identify the most important environmental variable to control if excessive algal growth is a management problem. The method also assesses the potential for future changes in nutrient availability to impact on the health of the stream by measuring the response of the algal communities to increased nutrient availability. 
Primary limitation by $\mathrm{N}$ of phytoplankton, macroalgae and seagrass growth has been demonstrated in the estuarine and marine sections of Brisbane River and Moreton Bay (Udy \& Dennison, 1997ba; Dennison \& Abal, 1999). This demonstrates that the reduction of $\mathrm{N}$ input to aquatic ecosystems in southeast Queensland should be a management focus. However, it is important to maintain balanced nutrient management of both $\mathrm{N}$ and $\mathrm{P}$ inputs into fresh and marine water bodies to prevent improving the competitive advantage of $\mathrm{N}$ fixing, and potentially toxic, cyanobacteria (Harris, 1997).

\section{Stable isotopes of nitrogen $\delta^{15} \mathrm{~N}$}

While the $\delta^{15} \mathrm{~N}$ value of aquatic plants was a better indicator than benthic sediment, based on the regression models and the spread of values, only half the sites had submerged aquatic plants present. Both aquatic plants and sediment samples have a similar technically difficult and cost to collect and prepare for analysis, but sediment was collected at more than $90 \%$ of the study sites. The models for both types of indicators contained similar descriptors and the relationship between $\delta^{15} \mathrm{~N}$ values of stream sediments and aquatic plants was significant, suggesting that both indicators respond to similar environmental factors. Hence, the current study sediment $\delta^{15} \mathrm{~N}$ value as being a more practical indicator for monitoring programs because of its applicability to a wider range of sites. 
The high $\delta^{15} \mathrm{~N}$ values observed in the current study 19\%o) are above the values of both raw and treated sewage (approximately 10\%; Dennison \& Abal, 1999; Waldron et al., 2001) and suggest that the stable isotopes of $\mathrm{N}$ in aquatic plants and sediment are responding to more than just an enriched point source of $\mathrm{N}$. Elevated $\delta^{15} \mathrm{~N}$ values may be a result of changes in the $\mathrm{N}$ cycle of the streams, including increased rates of denitrification. This is supported by the fact that the denitrification potential rate explained substantial portions of the variation in $\delta^{15} \mathrm{~N}$ values of aquatic plants and sediment in the current study and had a positive slope. A similar relationship with enriched $\delta^{15} \mathrm{~N}$ values of seagrass correlating with high denitrification rates in estuarine sediments has been demonstrated by Fourqurean et al. (1997). The fact that catchment land-use predicted a further portion of the variation in $\delta^{15} \mathrm{~N}$ values is also consistent with the findings of Udy and Bunn (2001) who reported a strong relationship between the $\delta^{15} \mathrm{~N}$ values of aquatic plants and the percentage of the catchment that had been cleared. Findings from the current study suggest that the $\delta^{15} \mathrm{~N}$ values of aquatic plants and sediment can be used in freshwater systems as an integrated measure of $\mathrm{N}$ cycling, and support previous work that the stable isotopes of $\mathrm{N}$ can be a useful monitoring tool to investigate anthropogenic changes to the nitrogen cycle in aquatic systems (Owens 1985; McClelland et al., 1997; McClelland \& Valiela 1998; Costanzo et al., 2005).

\section{Conclusions}

With the growing recognition of the importance of monitoring ecosystem function as well as structure, measures of ecosystem processes are starting to be included 
in regional stream ecosystem health monitoring (Hill et al., 2000; Abal et al., 2005). This study demonstrates the potential effectiveness of using nutrient process indicators to assess the impacts of a diffuse land-use disturbance gradient on stream ecosystem health in southeast Queensland. The $\delta^{15} \mathrm{~N}$ value of stream sediment is the best overall indicator of nutrient processes of the 7 trialled in this study, based on the evaluation of regression modelling results as well as practical aspects of applying the method. Samples are relatively easy to collect and prepare, relatively inexpensive to analyse, and are successfully obtained from the widest range of sites. Four other indicators (denitrification index, algal growth on artificial substrates with added $\mathrm{N}$ and $\mathrm{N}+\mathrm{P}$, and $\delta^{15} \mathrm{~N}$ of aquatic plants) were better in terms of the amount of variation explained by descriptors of the disturbance gradient, but were more difficult to apply for various reasons. Depending on the goals of a monitoring program, and the characteristics of the sites involved, multiple nutrient process indicators could be successfully implemented to yield complementary information about aspects of stream functioning.

\section{Acknowledgments}

This research was funded by the Moreton Bay Waterways and Catchment Partnership, with many members of the Centre for Catchment and In-Stream Research at Griffith University helping with field work. Kate Moore CWS, University of Queensland help with presentation of the figures. 


\section{References}

Abal, E. G., S. E. Bunn, and W. C. Dennison, (eds), 2005. Healthy Waterways, Healthy Catchments: Making the connection in south east Queensland, Australia. Moreton Bay Waterways and Catchments Partnership, Brisbane 240p.

Addison, R. F., and K. R. Clarke, 1990. The IOC/GEEP Bermuda workshop. Journal of Experimental Marine Biology and Ecology 138: 1-8.

Anderson, J. R., 1993. State of the Rivers Project. Report 1. Development and Validation of the Methodology. Report to the Department of Primary Industries, Queensland.

Bartkow, M. E., and J. W. Udy, 2004. Quantifying potential nitrogen removal by denitrification in stream sediments at a regional scale. Marine and Freshwater Research 55: 309-315.

Bayne, B. L., R. F. Addison, J. M. Capuzzo, K. R. Clarke, J. S. Gray, M. N. Moore, and R. M. Warwick, 1988. An overview of the GEEP workshop. Marine Ecology Progress Series 46: 235-243.

Bunn, S. E., P. M. Davies, and T. D. Mosisch, 1999. Ecosystem measures of river health and their response to riparian and catchment degradation. Freshwater Biology 41: 333-345.

Burford, M. A., and A. R. Longmore, 2001. High ammonium production from sediments in hypereutrophic shrimp ponds. Marine Ecology-Progress Series 224: 187-195.

Costanzo, S. D., M. J. O'Donohue, W. C. Dennison, N. R. Loneragan, and M. Thomas, 2001. A new approach for detecting and mapping sewage impacts. Marine Pollution Bulletin 42: 149-156.

Costanzo, S., J. W. Udy, B. Longstaff, A. Jones, 2005. Using nitrogen stable isotope ratios $\left(\delta^{15} \mathrm{~N}\right)$ of macroalgae to determine the effectiveness of sewage upgrades: changes in the extent of sewage plumes over four years in Moreton Bay, Australia. Marine Pollution Bulletin 51: 212-217

Davies, P. M., 1994. Ecosystem ecology of upland streams of the northern jarrah forest, Western Australia. Ph.D. thesis. The University of Western Australia.

Dennison, W. C., and E. G. Abal, 1999. Moreton Bay Study: A scientific basis for the healthy waterways campaign. South East Queensland Water Quality Management Strategy, Brisbane.

Fellows, C. S., J. E. Clapcott, J. W. Udy, S. E. Bunn, M. J. Smith, B. D. Harch, and P. M. Davies, this issue. Benthic metabolism as an indicator of stream ecosystem health. Hydrobiologia.

Fourqurean, J. W., T. O. Moore, B. Fry, and J. T. Hollibaugh, 1997. Spatial and temporal variation in $\mathrm{C}: \mathrm{N}: \mathrm{P}$ ratios, delta $\mathrm{N}-15$ and delta $\mathrm{C}-13$ of eelgrass Zostera marina as indicators of ecosystem processes, Tomales Bay, California, USA. Marine Ecology-Progress Series 157: 147-157.

Hadwen, W. L., S. E. Bunn, A. H. Arthington, and T. D. Mosisch, 2005. Withinlake detection of the effects of tourist activities in the littoral zone of oligotrophic dune lakes. Aquatic Ecosystem Health and Management 8: 159-173. 
Harris, G. P., 1997. Algal biomass and biogeochemistry in catchments and aquatic ecosystems: scaling of processes, models and empirical tests. Hydrobiologia 349: 19-26.

Heggie, D. T., G. W. Skyring, J. Orchardo, A. R. Longmore, G. J. Nicholson, and W. M. Berelson, 1999. Denitrification and denitrifying efficiencies in sediments of Port Phillip Bay: direct determinations of biogenic N-2 and $\mathrm{N}$-metabolite fluxes with implications for water quality. Marine and Freshwater Research 50: 589-596.

Hill, B. H., R. K. Hall, P. Husby, A. T. Herlihy, and M. Dunne, 2000. Interregional comparisons of sediment microbial respiration in streams. Freshwater Biology 44: 213-222.

Holmes, R. M., J. B. Jones, S. G. Fisher, and N. B. Grimm, 1996. Denitrification in a nitrogen-limited stream ecosystem. Biogeochemistry 33: 125-146.

Keithan, E. D., and R. L. Lowe, 1985. Primary productivity and spatial structure of phytolithic growth in streams in the Great Smoky Mountains National Park, Tennessee (USA). Hydrobiologia 123: 59-68.

Kennard, M. J., B. J. Pusey, A. H. Arthington, B. D. Harch, and S. J. Mackay, this issue. Utility of a multivariate modelling method for prediction of freshwater fish assemblages and evaluation of river health. Hydrobiologia.

Kevern, N. R., and R. C. Ball, 1965. Primary productivity and energy relationships in artificial streams. Limnology and Oceanography 10: 7487.

Knowles, R., 1982. Denitrification. Microbiologial Reviews 46: 43-70.

McClelland, J. W., and I. Valiela, 1998. Linking nitrogen in estuarine producers to land-derived sources. Limnology and Oceanography 43: 577-585.

McClelland, J. W., I. Valiela, and R. H. Michener, 1997. Nitrogen-stable isotope signatures in estuarine food webs: A record of increasing urbanization in coastal watersheds. Limnology and Oceanography 42: 930-937.

McKinney, R. A., J. L. Lake, M. A. Charpentier, and S. Ryba, 2002. Using mussel isotope ratios to assess anthropogenic nitrogen inputs to freshwater ecosystems. Environmental Monitoring and Assessment 74: 167-192.

Mosisch, T. D., S. E. Bunn, and P. M. Davies, 2001. The relative importance of shading and nutrients on algal production in subtropical streams. Freshwater Biology 46: 1269-1278.

Mosisch, T. D., S. E. Bunn, P. M. Davies, and C. J. Marshall, 1999. Effects of shade and nutrient manipulation on periphyton growth in a subtropical stream. Aquatic Botany 64: 167-177.

Mulholland, P. J., J. L. Tank, J. R. Webster, W. B. Bowden, W. K. Dodds, S. V. Gregory, N. B. Grimm, S. K. Hamilton, S. L. Johnson, E. Marti, W. H. McDowell, J. L. Merriam, J. L. Meyer, B. J. Peterson, H. M. Valett, and W. M. Wollheim, 2002. Can uptake length in streams be determined by nutrient addition experiments? Results from an interbiome comparison study. Journal of the North American Benthological Society 21: 544-560.

Nishio, T., I. Koike, and A. Hattori, 1983. Estimation of nitrification and denitrification in coastal and estuarine sediments. Applied and Environmental Microbiology 45. 
O'Donohue, M. J. H., and W. C. Dennison, 1997. Phytoplankton productivity response to nutrient concentrations, light availability and temperature along an Australian estuarine gradient. Estuaries 20: 521-533.

Owens, N. J. P., 1985. Variations in the natural abundance of $15 \mathrm{~N}$ in estuarine suspended particulate matter: a specific indicator of biological processing. Estuarine Coastal and Shelf Science 20: 505-510.

Parsons, T. R., Y. Maita, and C. M. Lalli, 1984. A Manual of Chemical and Biological Methods for Seawater Analysis. Pergamon Press, Oxford.

Peterson, B. J., and B. Fry, 1987. Stable Isotopes in Ecosystem Studies. Annual Review of Ecology and Systematics 18: 293-320.

Peterson, B. J., W. M. Wollheim, P. J. Mulholland, J. R. Webster, J. L. Meyer, J. L. Tank, E. Marti, W. B. Bowden, H. M. Valett, A. E. Hershey, W. H. McDowell, W. K. Dodds, S. K. Hamilton, S. Gregory, and D. D. Morrall, 2001. Control of nitrogen export from watersheds by headwater streams. Science 292: 86-90.

Pfenning, K. S., and P. B. McMahon, 1997. Effect of nitrate, organic carbon, and temperature on potential denitrification rates in nitrate-rich riverbed sediments. Journal of Hydrology 187: 283-295.

Rapport, D. J., R. Costanza, and A. J. McMichael, 1998. Assessing ecosystem health. Trends in Ecology \& Evolution 13: 397-402.

Rosgen, D. L., 1994. A Classification of Natural Rivers. Catena 22: 169-199.

Royer, T. V., J. L. Tank, and M. B. David, 2004. Transport and fate of nitrate in headwater agricultural streams in Illinois. Journal of Environmental Quality 33: 1296-1304.

Seitzinger, S. P., 1988. Denitrification in Fresh-Water and Coastal Marine Ecosystems : Ecological and Geochemical Significance. Limnology and Oceanography 33: 702-724.

Sloth, N. P., H. Blackburn, L. S. Hansen, N. Risgaardpetersen, and B. A. Lomstein, 1995. Nitrogen Cycling in Sediments with Different Organic Loading. Marine Ecology-Progress Series 116: 163-170.

Smith, M. J., and A. W. Storey, (eds), 2001. Design and Implementation of Baseline Monitoring (DIBM3): Developing an Ecosystem Health Monitoring Program for Rivers and Streams in Southeast Queensland. Report to the South-East Queensland Regional Water Quality Management Strategy, Brisbane.

Stebbing, A. R. D., and V. Dethlefsen, 1992. Introduction to the Bremerhaven workshop on biological effects of contaminants. Marine Ecology Progress Series 91: 1-8.

Strauss, E. A., and G. A. Lamberti, 2000. Regulation of nitrification in aquatic sediments by organic carbon. Limnology and Oceanography 45: 18541859.

Tank, J. L., and W. K. Dodds, 2003. Nutrient limitation of epilithic and epixylic biofilms in ten North American streams. Freshwater Biology 48: 10311049.

Tiedje, J. M., S. Simkins, and P. M. Groffman, 1989. Perspectives on measurement of denitrification in the field including recommended protocols for acetylene based methods. Plant and Soil 115: 261-284. 
Udy, J. W., and S. E. Bunn, 2001. Elevated delta N-15 values in aquatic plants from cleared catchments: why? Marine and Freshwater Research 52: 347351.

Udy, J. W., and W. C. Dennison, 1997a. Physiological responses of seagrasses used to identify anthropogenic nutrient inputs. Marine and Freshwater Research 48: 605-614.

Udy, J. W., and W. C. Dennison, 1997b. Growth and physiological responses of three seagrass species to elevated sediment nutrients in Moreton Bay, Australia. Journal of Experimental Marine Biology and Ecology 217: 253277.

Van Luijn, F., P. Boers, L. Lijklema, and J. Sweerts, 1999. Nitrogen fluxes and processes in sandy and muddy sediments from a shallow eutrophic lake. Water Research 33: 33-42.

Vanderborght, J., and G. Billen, 1975. Vertical distribution of nitrate concentration in interstitial water of marine sediments with nitrification and denitrification. Limnology and Oceanography 20: 953-961.

Waldron, S., P. Tatner, I. Jack, and C. Arnott, 2001. The impact of sewage discharge in a marine embayment: A stable isotope reconnaissance. Estuarine Coastal and Shelf Science 52: 111-115.

Wayland, M., and K. A. Hobson, 2001. Stable carbon, nitrogen, and sulfur isotope ratios in riparian food webs on rivers receiving sewage and pulp-mill effluents. Canadian Journal of Zoology-Revue Canadienne De Zoologie 79: 5-15.

Weiss, R. F., and B. A. Price, 1980. Nitrous oxide solubility in water and seawater. Marine Chemistry 8: 347-359. 
Table 1: Categories of disturbance gradient descriptors and the specific descriptors chosen for use in generalised linear regression modelling of nutrient processing indicators. See text for a more detailed description of the methods used to quantify the descriptors.

\section{Descriptor Category}

Descriptor Explanation

\section{Land-use (Catchment scale)}

$\%$ Cleared

Percentage of total catchment area cleared

Land-use Category

Categorical variable Scale $0-4$ ( $0=$ Urban; $4=$ natural or undisturbed $)$

\section{Channel Conditions (Reach scale)}

Channel condition

Categorical variable, Scale 1-4, (1 = highly degraded, $4=$ natural $)$

\section{Riparian Conditions (Reach scale)}

Hemiphot cover

Riparian vegetation
Measure of \% riparian canopy cover at the specific site of benthic metabolism measurements calculated using fish-eye lens (hemi) photography

Categorical variable, Scale $0-4$, where $0=$ No riparian vegetation, $4=$ Excellent riparian vegetation

\section{Water/sediment chemistry (Reach and catchment scale)}

$\begin{array}{ll}\text { Maximum temperature } & \begin{array}{l}\text { Maximum water temperature recorded by data logger over } 24 \text { hours in } \\ \text { open water }\end{array} \\ \% \mathrm{C} \text { in sediment } & \text { sample after being heated to } 400^{\circ} \mathrm{C}\end{array}$

The six descriptors below are based on laboratory analyses of water samples taken at the time process measures were made in the field.
Ions gradient (PCA 1)
PCA variable 1 explained $53 \%$ of the variation in site water chemistry and represented inorganic ions
$\mathrm{NO}_{3}{ }^{-}+\mathrm{NO}_{2}^{-}$
Dissolved nitrate + nitrite-N concentration expressed as an index 1-5
$\mathrm{NH}_{4}^{+}$
( 1 = lowest concentration, 5 = highest concentration)
$\mathrm{PO}_{4}{ }^{-3}$
Dissolved ammonium-N concentration expressed as an index 1-4
( 1 = lowest concentration, 4 = highest concentration)
Filterable reactive phosphate expressed as an index 1-11
$\mathrm{TN}$
( 1 = lowest concentration, $11=$ highest concentration $)$
Total $\mathrm{N}$ expressed as an index 1-4
( 1 = lowest concentration, $4=$ highest concentration $)$
$\mathrm{TP}$
Total phosphate expressed as an index 1-5
( 1 = lowest concentration, 5 = highest concentration $)$

\section{In-stream habitat (Reach Scale)}

$\%$ Fine sediment The $\%$ of the total sediment composed of mud and silt

\section{Flow related -none included}


Table 2 Approximate $\mathrm{R}^{2}$ values from regression models of potential nutrient process indicators against descriptors of the disturbance gradient that relate to land-use, channel condition, riparian cover, water and sediment chemistry, and in-stream habitats.

\section{Disturbance gradient categories}

\begin{tabular}{|c|c|c|c|c|c|c|}
\hline Nutrient Indicators & 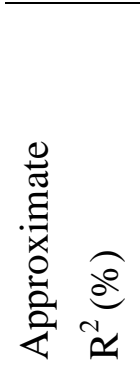 & 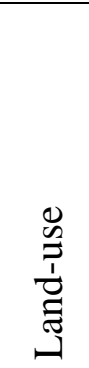 & 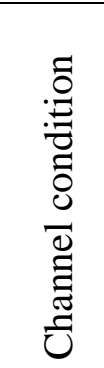 & 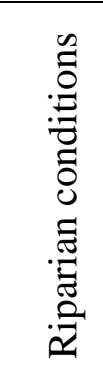 & 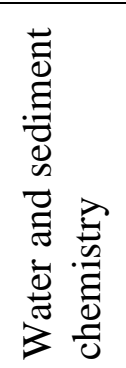 & 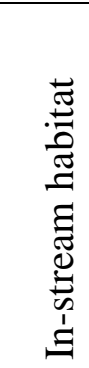 \\
\hline Denitrification & 51 & 1 & NS & NS & 45 & 5 \\
\hline Denitrification/\%Carbon & 79 & NS & NS & NS & $79^{\dagger}$ & NS \\
\hline $\begin{array}{l}\text { Algal growth on }+\mathrm{N} \text { substrate } \\
(\mathrm{Chl} a)\end{array}$ & 80 & NS & NS & 27 & 26 & 27 \\
\hline $\begin{array}{l}\text { Algal growth on }+\mathrm{P} \text { substrate } \\
(\mathrm{Chl} a)\end{array}$ & 37 & NS & NS & 15 & 22 & \\
\hline $\begin{array}{l}\text { Algal growth on }+\mathrm{NP} \text { substrate } \\
(\mathrm{Chl} a)\end{array}$ & 68 & NS & NS & 33 & 2 & 33 \\
\hline$\delta^{15} \mathrm{~N}$ (plants) & 80 & 13 & NS & NS & $67^{*}$ & NS \\
\hline$\delta^{15} \mathrm{~N}$ (sediment) & 62 & 7 & NS & NS & $55^{\ddagger}$ & NS \\
\hline
\end{tabular}


Figure 1 Rates of denitrification potential measured in the stream sediment ( $\mu$ mol $\left.\mathrm{N} \mathrm{m}^{-2} \mathrm{~h}^{-1}\right)$ plotted against the organic carbon content of the sediment $(\% \mathrm{C})$.

Figure 2 Regression modelling results for denitrification index (denitrification potential rate/\% $\mathrm{C}$ in sediment). Measured values are plotted against the modelled values using a model of disturbance gradient descriptors developed in a Generalised Linear Modelling (GLM) framework using stepwise regression modelling. $\quad \log _{10}$ (denitrification index +1 ) transformation was used for modelling.

Figure 3 Regression modelling results (GLM) for chlorophyll $a$ concentrations on artificial substrates with one of three nutrient addition treatments: $(\bullet)+\mathrm{N},(\mathrm{O})+\mathrm{P}$, and $(\square) \mathrm{N}+\mathrm{P}$. The transformation $\log _{10}$ (chlorophyll $a+3$ ) was used for modelling and untransformed units are mg chlorophyll $a \mathrm{~m}^{-2}$.

Figure 4 Relationship between $\delta^{15} \mathrm{~N}$ values of aquatic plants (filamentous algae or macrophytes) and $\delta^{15} \mathrm{~N}$ values of sediment (\%o). Results of simple linear regression analysis are shown with a best-fit line.

Figure 5 Regression modelling results (GLM) for $\delta^{15} \mathrm{~N}$ values of aquatic plants (algae or macrophytes). The transformation $x+2$ was used in the model and the untransformed units are \%o. 